\title{
A Novel Interactive Virtual Medical Student Clinical Rotation for Ophthalmology
}

\author{
James Frisbie, MD ${ }^{1}$ Hannah Cornman, $\mathrm{BS}^{1} \quad$ Ramya Swamy, MD, MPH ${ }^{1}$ Janet Leath Alexander, $\mathrm{MD}^{1}$ \\ Pavlina S. Kemp, MD ${ }^{2}$ Rebekah Friedrich, MS, RN, CCRN, CPPS 3 Colleen A. Hughes Driscoll, MD ${ }^{4}$ \\ Moran R. Levin, MD ${ }^{1}$
}

1 University of Maryland School of Medicine, Baltimore, Maryland

2 University of lowa, Department of Ophthalmology, lowa City, lowa

${ }^{3}$ Department of Clinical Engineering, University of Maryland Medical Center, Baltimore, Maryland

${ }^{4}$ Department of Pediatrics, University of Maryland, Baltimore, Maryland

J Acad Ophthalmol 2022;14:e52-e59.
Address for correspondence Moran Levin, MD, Department of Ophthalmology and Visual Sciences, University of Maryland School of Medicine, 419 W. Redwood Street, Suite 470, Baltimore, MD 21201 (e-mail: rlevin@som.umaryland.edu).
Abstract
Keywords
- technology
- curriculum
- medical student education
- surgical curriculum
- surgical teaching
- ophthalmology rotation
- surgical skills

Objective This article describes a novel clinical rotation that uses technology to create a remote ophthalmology learning experience with the goal of improving virtual exposure to medical and surgical ophthalmic training for medical students.

Methods Our unique curriculum incorporates mobile-mounted tablets which allow students to virtually participate in inpatient consults, clinic, and ophthalmic surgery. An adaptable mounting device attached to the slit lamp allows students to observe examinations in real time, enhancing recognition of ocular pathologies. Students participate in a robust curriculum that includes independent learning modules, video lectures, interactive modules, podcasts, and surgical video rounds. Students engage with residents and faculty in interactive-guided lectures and case-based discussions that focus on the American Academy of Ophthalmology white paper teaching objectives. Students are mailed surgical instruments and participate in surgical modules and faculty-led virtual wet laboratories.

Results Our unique virtual curriculum combines didactic learning, interactive content, and novel technology applications such as mobile tablets, slit lamp-mounted devices, and faculty-led virtual wet laboratories.

Conclusion Virtual technologies can be utilized to enhance ophthalmology medical student education in a safe and effective way during the coronavirus disease 2019 pandemic, and to improve educational access in the future.

Virtual medical education (VME) is a term that includes asynchronous instruction, telemedicine, video libraries, and conference records, among other methods. ${ }^{1}$ While VME approaches have steadily increased in medical schools across the United States in the last two decades, the onset of

received

January 19, 2021 accepted after revision November 24, 2021
DOI https://doi.org/ $10.1055 / \mathrm{s}-0042-1743410$ ISSN 2475-4757. the coronavirus disease 2019 (COVID-19) pandemic catalyzed an even faster transition, as educators attempted to find ways to minimize interruptions to medical education while maintaining or improving educational goals. Many medical schools now utilize asynchronous instruction that

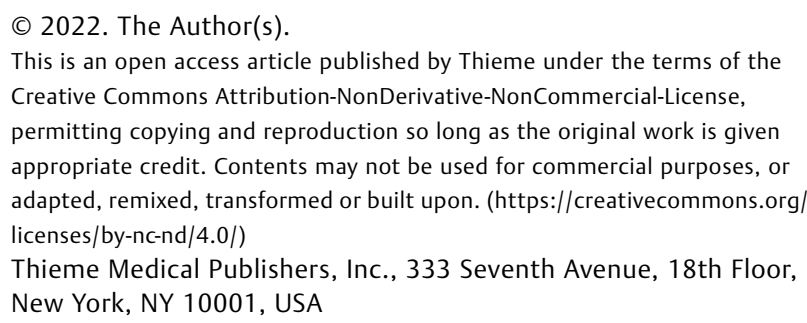


allows students to view and work at their own pace during didactic education, as well as employ surgery libraries to allow exposure to surgical procedures and techniques., 2,3 Some schools have even developed remote methods for observing technical skills practiced at home via GoPro video recordings. 4

In fields such as surgery, ${ }^{5}$ dermatology, ${ }^{6}$ and rheumatology, ${ }^{7}$ virtual consults through telemedicine have not only allowed safe, effective patient care, but have also facilitated educational instruction during the time in which our world has been affected by the COVID-19 pandemic. $^{8}$ These methods have also allowed students to contribute to the pandemic response. For example, at some medical institutions, medical students have helped to relieve clinical workloads by fielding virtual video-based triages for patients presenting to the emergency department. ${ }^{9}$ In addition to benefiting students and educators, patients report being particularly receptive to the use of technology in their care in an academic setting. ${ }^{6}$

The American University Professors of Ophthalmology and American Academy of Ophthalmology (AAO) recently published a white paper detailing medical student ophthalmic learning objectives, which revolve around the basic understanding of different ophthalmic diseases. ${ }^{10}$ The ability to meet those learning objectives was challenged in March of 2020, when medical student clinical rotations were suspended following the recommendation of the Association of American Medical Colleges in response to the COVID-19 pandemic. ${ }^{11}$ Following this recommendation, most institutions highly discouraged or even prohibited in-person away rotations due to public health concerns for a significant period of time. This caused a reduction in direct medical student exposure to patients and posed a challenge to ophthalmic education. Thus, with the understanding that the privilege of in-person education can be interrupted by such adverse circumstances, it is now more important than ever for innovations that increase student exposure to ophthalmology and refine virtual teaching methods.

A review of virtual teaching resources for ophthalmology indicates that there is a wide variety of methods available or in development. ${ }^{12}$ These include online learning modules, video tutorials teaching clinical skills, ${ }^{13}$ virtual reality tools, ${ }^{14}$ and simulated eye conditions on virtual patients. ${ }^{15}$ Although these methods are beneficial to student education, none can replicate the interaction with real patients, observation of surgeries and physical exam techniques, and support and mentorship that are integral to in-person ophthalmology rotations. Many programs are adapting by creating virtual elective rotations to fill these gaps. ${ }^{16-18}$ These virtual electives have allowed for medical student exposure to specialty care during the COVID-19 pandemic, with the additional benefit of reducing personal protective equipment use and exposure to the virus. ${ }^{19}$

Virtual rotations have the potential to benefit medical students and programs by improving access to and reducing costs of medical education, even beyond the pandemic. One possible realization of this potential would be the creation of virtual away rotations. Surveys have found that 70 to $90 \%$ of ophthalmology residency applicants participate in at least one away rotation, and the estimated cost of a single away rotation in ophthalmology ranges from $\$ 990$ to $\$ 1,700 .^{20-22}$ This cost can be prohibitive and likely disproportionately impacts students with limited financial resources. Saving on housing, transportation, and cost of living with virtual away rotations would reduce student debt as well as financial barriers to entering ophthalmology. ${ }^{21}$ Reducing these barriers may ultimately have an impact on the diversity of applicants who choose to pursue this profession.

Another potential benefit of virtual electives is improved educational access. Although there are over 180 allopathic and osteopathic medical schools in the United States, ${ }^{11}$ there are less than 120 ophthalmology residency programs in the country. Students at schools without a home ophthalmology program would benefit from a virtual rotation elsewhere. In addition to facilitating away rotations, virtual rotations may also increase the number of students that can rotate on a service at any given time, thus allowing students at a home program to attend grand round conferences, participate in telemedicine, or virtually attend clinic and surgical operations. $^{23}$ By increasing the number of students who can participate in an ophthalmology rotation, virtual rotations could also increase exposure to ophthalmology among students who do not pursue a career in the field. This would be beneficial because it has been shown that limited ophthalmic education in medical school increases the likelihood of future medical mismanagement and overreferral of simple eye disorders. ${ }^{24,25}$

Finally, ophthalmology as a specialty often struggles to recruit a diverse student body to their residency classes. ${ }^{26}$ The reasons for this are multifactorial but often have to do with limited exposure to the specialty in the preclinical and clinical years of medical training. The use of virtual rotations has the potential to introduce ophthalmology to a wider student body at an earlier time in their clinical training.

In addition to the value provided to students, virtual rotations have the potential to help academic ophthalmologists make informed decisions regarding the match process. As in other surgical fields, over $50 \%$ of students matched at a program where they completed an away rotation. ${ }^{27}$ For instance, in the otolaryngology residency process, one of the three criteria regarding candidate selection included rotation at that specific institution. ${ }^{28}$ Similarly, in plastic surgery, interactions with residents and faculty was the single most important activity to candidates. ${ }^{19}$ A virtual curriculum in ophthalmology may allow increased time between students, residents, and faculty, allowing all stakeholders in the match process to better determine the fit for a particular program.

In this article, we detail the development of a virtual ophthalmology rotation piloted at the University of Maryland School of Medicine. It is our hope that this virtual rotation will not only serve a purpose during the COVID19 pandemic and expand VME in the field of ophthalmology, but introduce a strategy with long-lasting benefits, and contribute to the body of teaching strategies for medical educators across disciplines. 
Table 1 Sample weekly schedule

\begin{tabular}{|l|l|l|l|l|}
\hline Monday & Tuesday & Wednesday & Thursday & Friday \\
\hline $\begin{array}{l}\text { 7-8 a.m. } \\
\text { resident lecture }\end{array}$ & $\begin{array}{l}\text { 7:30-8:30 a.m. } \\
\text { grand rounds }\end{array}$ & $\begin{array}{l}\text { 7-8 a.m. } \\
\text { resident lecture }\end{array}$ & $\begin{array}{l}7-8 \text { a.m. } \\
\text { resident lecture }\end{array}$ & \\
\hline $\begin{array}{l}8: 30-9 \text { a.m. chair } \\
\text { rounds }\end{array}$ & $\begin{array}{l}9 \text { a.m. }-12 \text { p.m. } \\
\text { independent } \\
\text { learning }\end{array}$ & $\begin{array}{l}8 \text { a.m. }-12 \text { p.m. } \\
\text { independent learning } \\
\text { independent } \\
\text { learning }\end{array}$ & $\begin{array}{l}8 \text { a.m. }-12 \text { p.m. } \\
\text { independent learning }\end{array}$ & $\begin{array}{l}8 \text { a.m. }-12 \text { p.m. } \\
\text { independent learning }\end{array}$ \\
\hline & $\begin{array}{l}12 \text { p.m. }-1 \text { p.m. } \\
\text { resident led lecture }\end{array}$ & $\begin{array}{l}12 \text { p.m. }-1 \text { p.m. } \\
\text { interactive faculty } \\
\text { teaching session }\end{array}$ & $\begin{array}{l}12 \text { p.m. }-1 \text { p.m. } \\
\text { interactive suture laboratory }\end{array}$ \\
\hline $\begin{array}{l}1-4 \text { p.m. } \\
\text { live virtual clinic }\end{array}$ & $\begin{array}{l}1-4 \text { p.m. } \\
\text { live consult rounds }\end{array}$ & $\begin{array}{l}1-4 \text { p.m. } \\
\text { live virtual clinic }\end{array}$ & $\begin{array}{l}1-4 \text { p.m. } \\
\text { live consult rounds }\end{array}$ & $\begin{array}{l}1 \text { p.m. } \\
\text { surgery observation }\end{array}$ \\
\hline
\end{tabular}

\section{Setting}

A 4-week ophthalmology elective was designed at the University of Maryland School of Medicine Department of Ophthalmology and Visual Sciences. Our unique curriculum incorporates mobile-mounted tablets, allowing students to virtually participate in inpatient consults, outpatient clinics, and ophthalmic surgery. An adaptable mounting device attached to the slit lamp allows students to observe examinations in real time, enhancing recognition of ocular pathologies. Students participate in a robust curriculum that includes independent learning modules, video lectures, interactive modules, podcasts, and surgical video rounds. Students engage with residents and faculty in interactiveguided lectures and case-based discussions that focus on the AAO white paper teaching objectives. Students are mailed surgical instruments and participate in prerecorded surgical modules and faculty-led virtual wet laboratories.

\section{Results}

In the following sections, each component of the virtual curriculum will be described individually. To see a sample full week schedule of a virtual student, please see - Table 1. Prior to the start of the elective, faculty were instructed via virtual preparation sessions to teach students during clinical and surgical encounters as if they were present in person. At this time, they were also briefed on expectations regarding presentation of virtual teaching and wet laboratory sessions.

\section{Mobile Virtual Rounding}

The ophthalmology department works closely with the clinical mobility team to utilize mobile iPad devices with secure Health Insurance Portability and Accountability Act of 1996 compliant networking to allow virtual students to observe consults in the hospital by logging into a Zoom session (-Fig. 1). Zoom is a popular cloud-based teleconferencing app that allows users to connect online for video and telephone communications. The students can see and hear the environment projected to them from the iPad camera and speakers, and they are visible and audible to faculty and patients via the video and audio transmitted from their computer or mobile device. The mobile iPad devices are wheeled with the consult team around the hospital in a variety of settings, including the pediatric and adult emergency department, inpatient services, and the shock trauma center, allowing virtual students to accompany faculty and residents. To simulate an in-person learning environment, students observe as residents obtain a detailed history and differential diagnosis and verbalized physical exam findings to allow medical students to come up with assessments and plans in real time (-Fig. 2). Students also participate in attending staffing of consults and actively contribute to clinical discussions.

\section{Virtual Clinic}

Once again, mobile tablets (iPads) are utilized to allow students to participate in clinical encounters at general ophthalmology and various subspecialty clinics by connecting them via Zoom. Subspecialty clinics include glaucoma, retina, cornea, uveitis, neuro-ophthalmology, pediatric, and oculoplastics. During both faculty and resident clinics, the mobile iPads are wheeled to each patient room and virtual students are introduced to the patients. The students can then take histories from patients and present to the attendings or residents, thus actively participating in patient care. Additional learning opportunities are facilitated by virtual students asking residents and attending faculty questions throughout clinical encounters ( - Fig. $\mathbf{3}$ ), as well as faculty pointing out interesting exam findings which can be viewed by slit lamp-mounted devices that share the image directly to the virtual video platform. These devices allow in-person students (-Fig. 4) and virtual students to observe physical exams simultaneously (-Fig. 5 ).

\section{Live Surgical Observation}

In addition to watching surgical video libraries and participating in discussions of challenging resident surgical cases during 


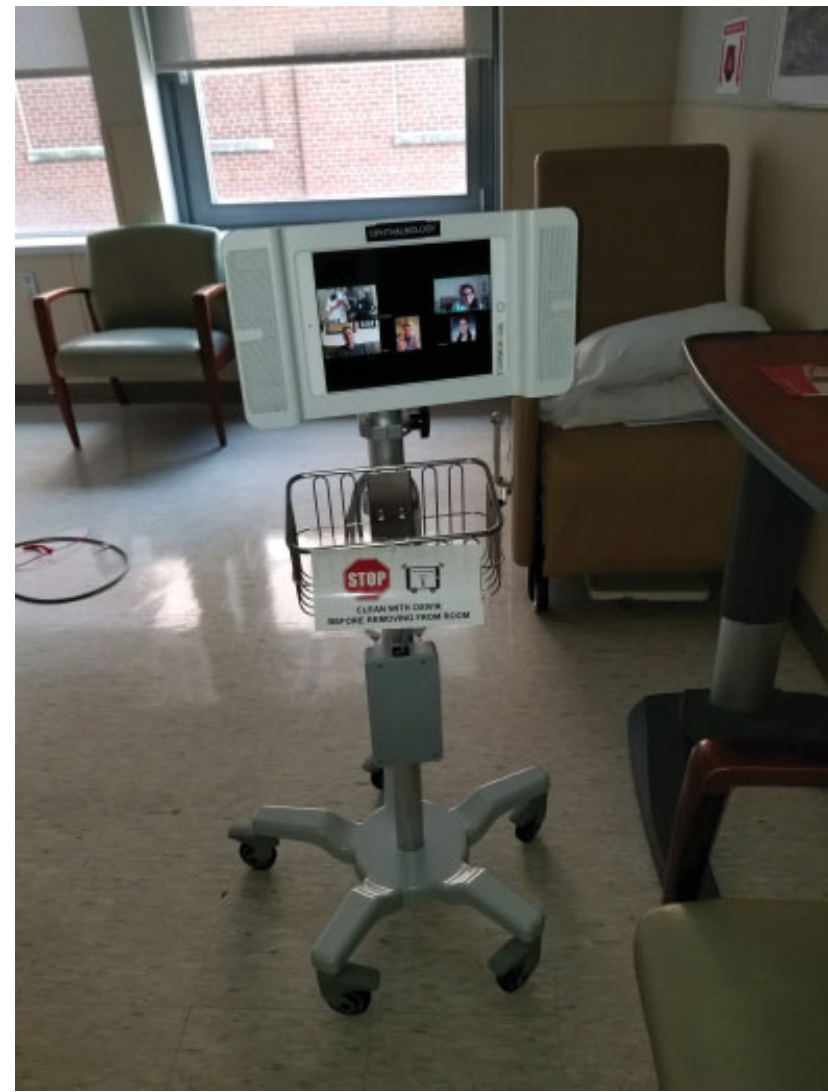

Fig. 1 Mobile iPads were allowed students to virtually attend consults throughout the hospital.

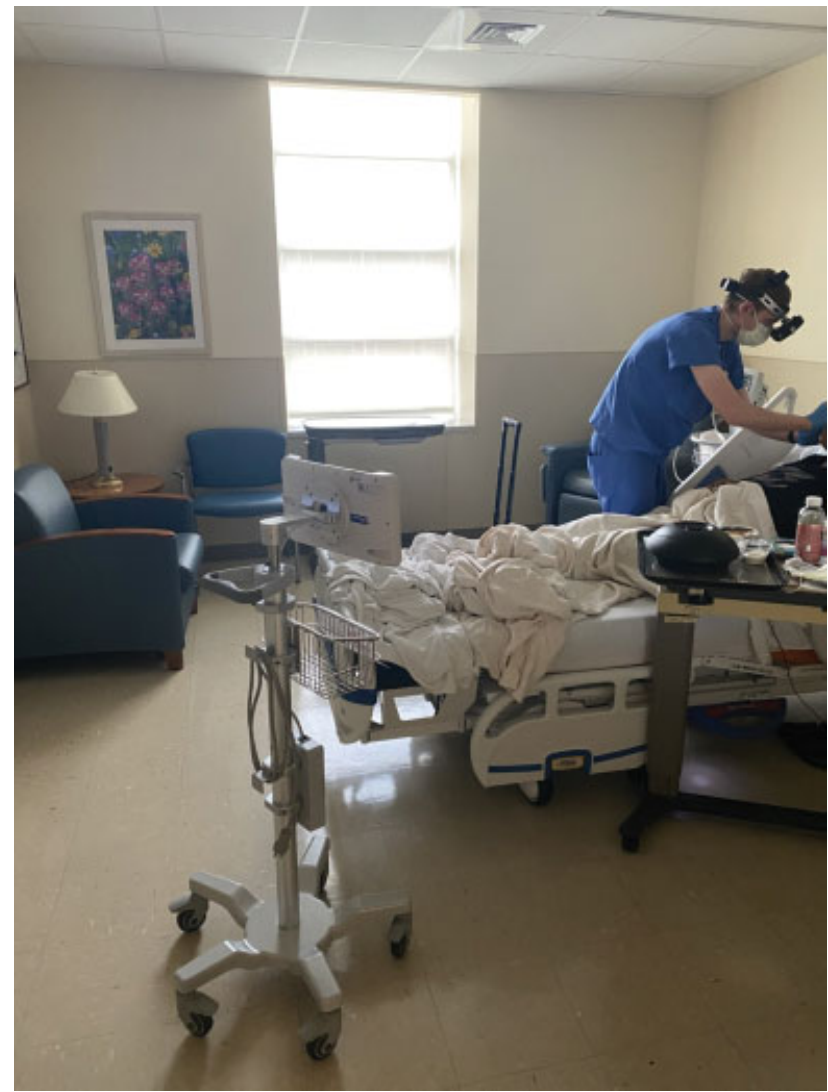

Fig. 2 Residents verbalized physical exam findings to allow virtual students to come up with live-time assessment and plans for patient.

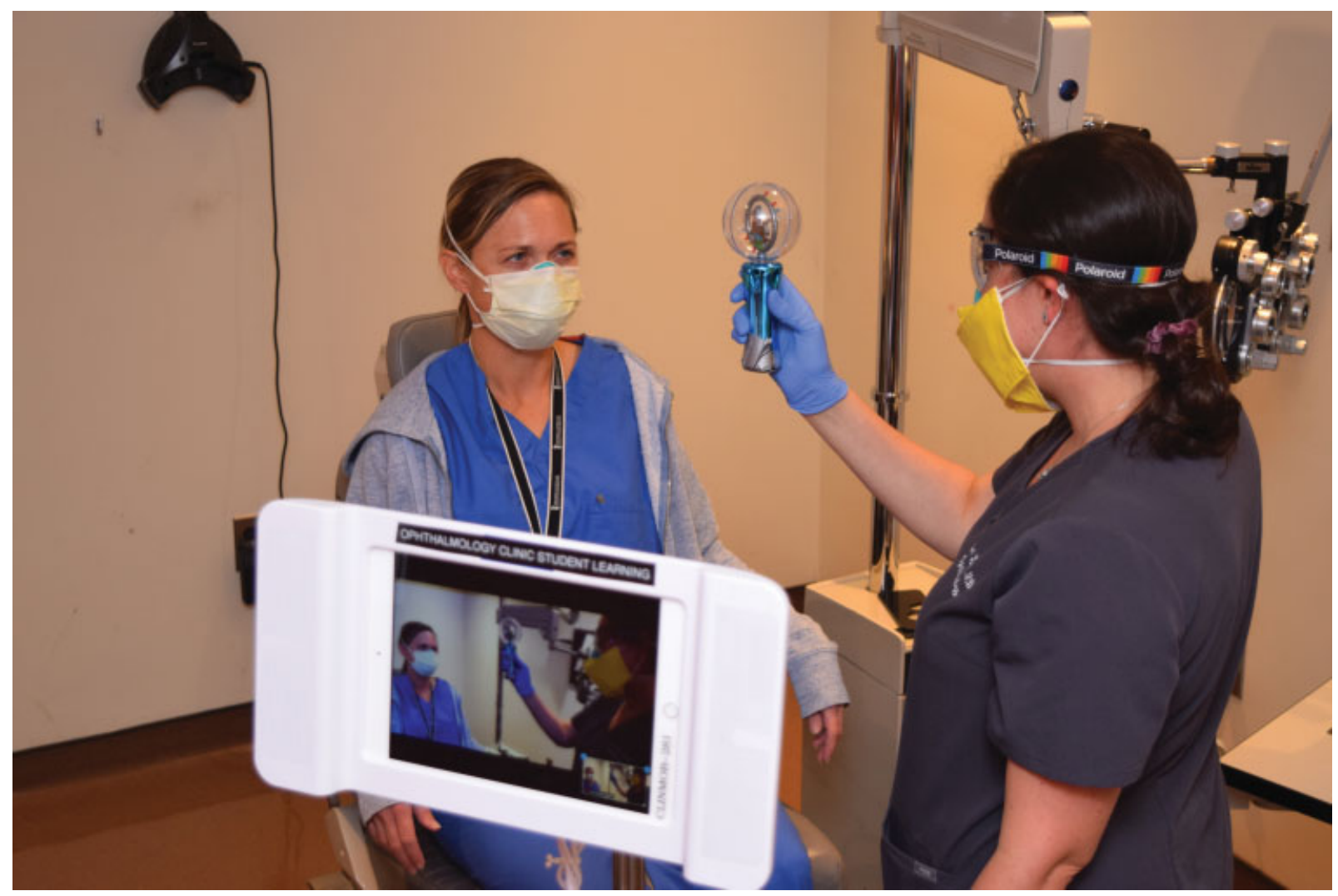

Fig. 3 Virtual students were able to observe clinical encounters in the clinic. 


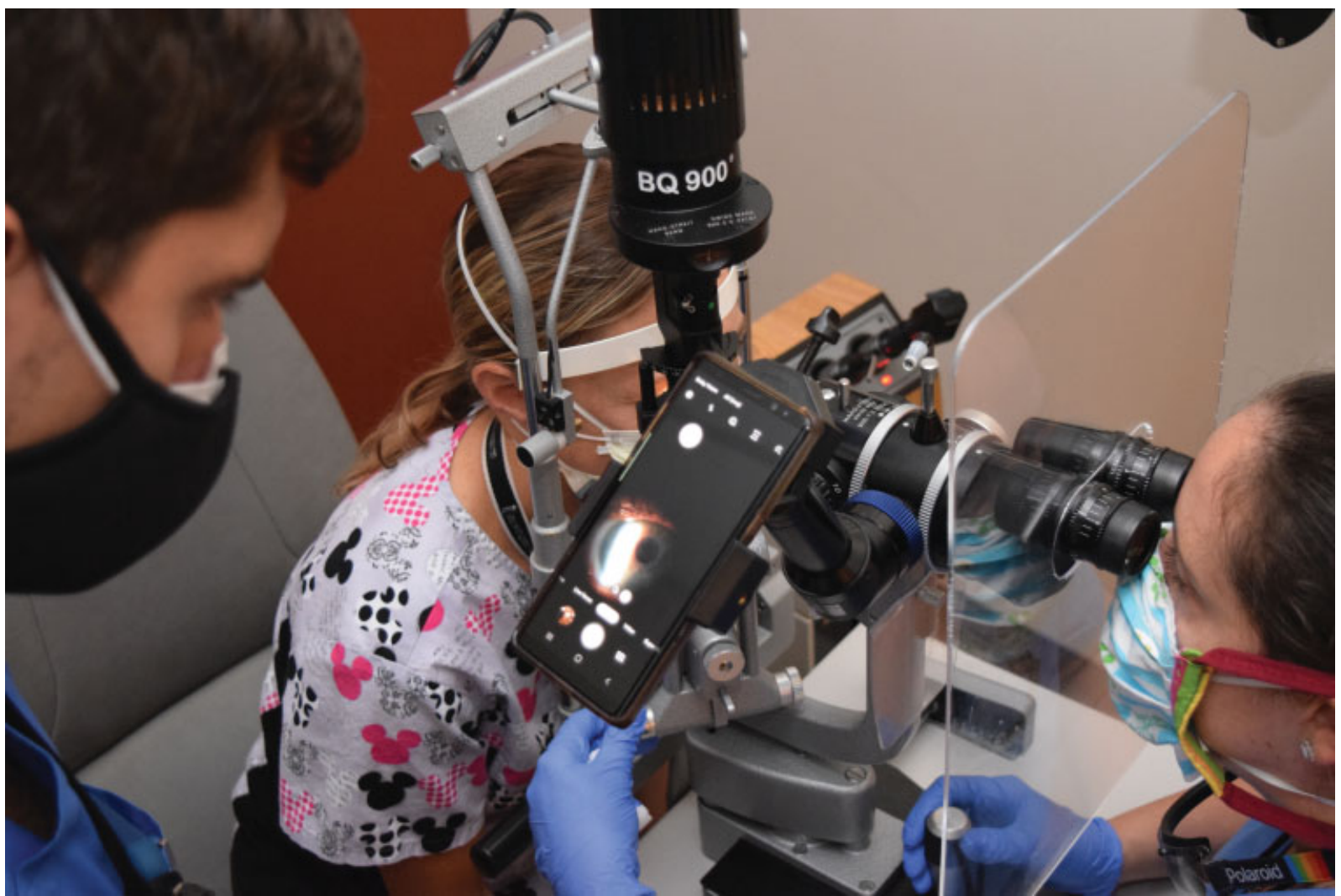

Fig. 4 Both in-person and virtual students were able to watch slit lamp examinations simultaneously.

departmental chair rounds, virtual students participate in remote surgical observation over the course of the rotation, typically one-half session per week. The mobile tablet allows virtual students to view video screens situated within the operating room throughout surgery and to engage with residents and attendings in real time during surgery (-Fig. 6).

\section{Independent Learning}

Throughout the course of the month, students are assigned both a combination of readings on basic ophthalmology, as well as video lectures and interactive content.

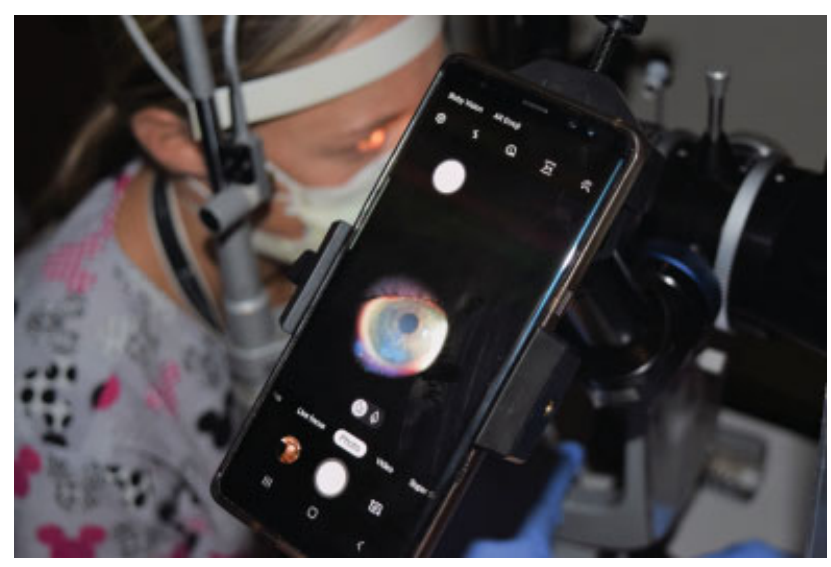

Fig. 5 Slit lamp images allowed students to visualize different eye pathologies. Cell phones used Zoom "screening-sharing" feature so all virtual students were able to observe through teaching scope.
Required readings are taken from the book "Basic Ophthalmology for Medical Students" by Cynthia A. Bradford, and include topics such as eye examinations, acute and chronic vision loss, neuro-ophthalmology, and eyelid, orbital, and lacrimal disease. ${ }^{29}$ Other supplementary readings are also provided and are often interactive in nature as discussed below.

Video lectures range from 8 to 35 minutes and are assigned throughout the rotation. During the first few weeks of lectures, videos focus on eye anatomy, basic eye, and slit lamp examinations and optics. As the course progresses, video lectures include more in-depth pathophysiology, including pediatric ophthalmology, leukocoria, retinoblastoma, diplopia, and cranial neuropathies.

Interactive content is also utilized throughout the rotation, and includes online anatomy quizzes, AAO case studies, ${ }^{30}$ and eye cases from the ophthalmology department at Indiana University. ${ }^{31}$ Finally, students listen to the "Eyes for Ears" podcast throughout the rotation and write up mock patient notes based on online cases. ${ }^{32}$ Every month, feedback from students is elicited to help determine any updates to the online content as necessary to maximize their online experience (-Fig. 7 ).

\section{Virtual Teaching Sessions with Faculty}

Virtual students participate in interactive teaching sessions with faculty from various subspecialists within the ophthalmology department. These teaching sessions are interactive and allow students a more personalized experience with 


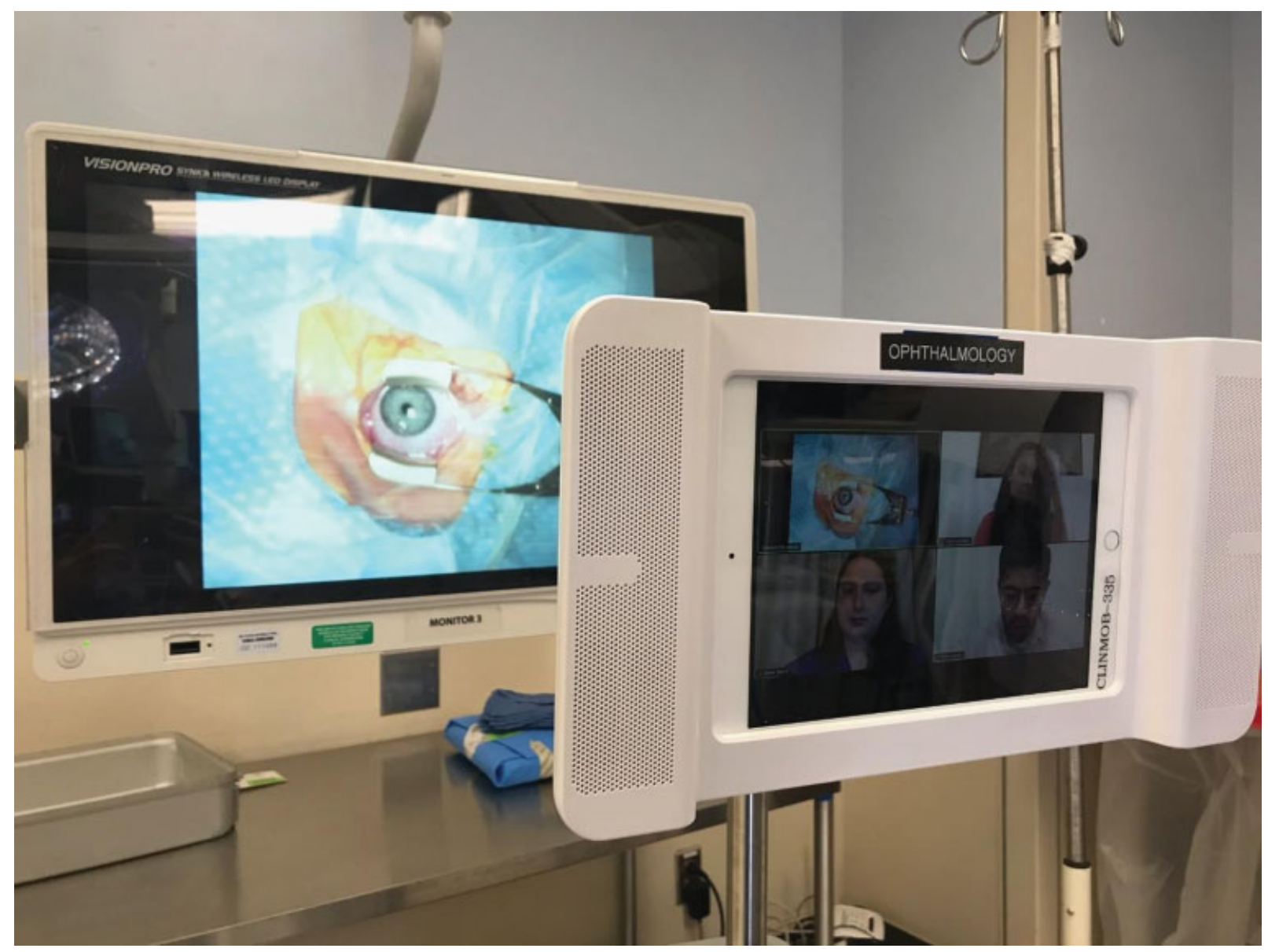

Fig. 6 iPad devices were placed to allow students to view surgeries in real time in the operating room. Devices were also placed close enough to allow engagement between the virtual students, residents, and attending physicians.

faculty. Topics include pediatric ophthalmology, acute vision loss, chronic vision loss, oculoplastics, and neuroophthalmology.

\section{Virtual Surgical Wet Laboratories with Faculty}

Students are instructed on basic principles of ophthalmic surgery and suturing techniques during faculty-led wet laboratories held on Zoom. Students participating in the virtual rotation are mailed instrument sets which include single-use Westcott scissors, Castroviejo needle holders, and $0.5 \mathrm{~mm}$ forceps purchased from Blink Medical along with materials to practice suturing such as fabric with cut slits and foam packing peanuts ( $\boldsymbol{- \text { Fig. }}$ 8). Throughout the course of the rotation, students are assigned weekly wet laboratory techniques to practice based on instructional videos, with the goal of gaining surgical skills that students would develop in the operating room during an in-person rotation. Students then receive suturing instruction from faculty members during the virtual surgical wet laboratories to ensure proper technique and approach. Participants aim the camera at their hands while suturing, while feedback and instruction is given in real time.

\section{Virtual Grand Rounds}

Both the in-person and virtual students participate in weekly grand rounds. At the conclusion of their rotations, all students perform a case presentation for faculty and residents.

\section{Conclusion}

Virtual technologies can be utilized to enhance ophthalmology medical student education in a safe and effective way during the COVID-19 pandemic and beyond. Independent study materials allow students to learn at their own pace and build upon their foundation of clinical knowledge, and mobile iPads allow them to apply this knowledge during real patient encounters. The use of technology in the clinic, hospital consult service, and the operating room greatly enhances the value of the rotation by allowing real-time evaluation of patients, increased interactions with residents and faculty, and integration of both an academic and clinical experience for the students. This technology can be utilized in the future not only to help increase exposure to the field, but help limit costs associated with traveling for rotations and create time-efficient opportunities for students wishing to gain ophthalmologic clinical experiences. 
Week 3: Pediatric Ophthalmology, Drugs and the Eve, Ocular Iniurr

Required Reading:

Ocular and Orbital Injuries

Amblyopia and Strabismus

Drugs and the Eye

Video Lectures:

Pediatric Ophthalmology: Amblyopia and Strabismus (23m)

Online MedEd: Peds Ophtho (16m)

Drugs and the Eve $(27 \mathrm{~m})$

Ocular and Orbital Iniuries $(30 \mathrm{~m})$

The Pediatric Eve Exam Levin $(8 \mathrm{~m})$

Leukocoria AAO $(8 \mathrm{~m})$

ROPAAO Levin $(8 \mathrm{~m})$

Amblyopia AAO $(8 \mathrm{~m})$

Retinoblastoma AAO $(8 \mathrm{~m})$

Pediatric Cataracts AAO $(8 \mathrm{~m})$

Surgical Videos:

Strabismus surgery $(6 \mathrm{~m})$

Interactive Content:

Interactive Medical Student Case Ocular Trauma

Cases: A. B Eyes for Ears Podcast.

Medication Quiz

IU Cases: A B

Eyes Have It Trauma Quiz

Assignments :

Patient note 3- due Friday at noon

Virtual Consults- 3 virtual consults with consult resident or faculty (anytime during week)

Individual learning reflection- due Friday at noon

Peds Quiz AAO videos

\section{Zoom Meetings:}

Virtual Grand Rounds Tuesday 7:30 am

Check in with faculty advisor to discuss scholarly project

Faculty Discussion Pediatric Ophthalmology: Amblyopia and Strabismus - Levin

Discussion: Ocular and Orbital Injuries-Swamy

Fig. 7 Example of curriculum portion for independent learning during virtual clinical elective.

The ability of this elective to expand the reach of ophthalmologic education is evidenced by the fact that students applying into various specialties (Family Medicine, Pediatrics, Internal Medicine, Obstetrics-Gynecology) and from all over the country (California, Hawaii, and Puerto Rico) have successfully completed it since its inception. The rotation has also been flexible enough to accommodate the various time zone differences these students experienced. Additionally, this same technology and approach was used to hold shadowing sessions with over 40 first- and second-year medical students interested in ophthalmology, thus increasing early exposure to the field.

Upon completion of the rotation, students are encouraged to give feedback on their experiences. Each month, the curriculum is updated to reflect feedback to improve and strengthen the curriculum. In the future we plan to collect qualitative data on the efficacy of this rotation on increasing interest and understanding of ophthalmologic knowledge.

\section{Conflict of Interest}

The authors have no financial interest related to this project.

\section{Acknowledgments}

The authors thank the University of Maryland Clinical Mobility Team for technical support and the use of mobile iPads for this project.

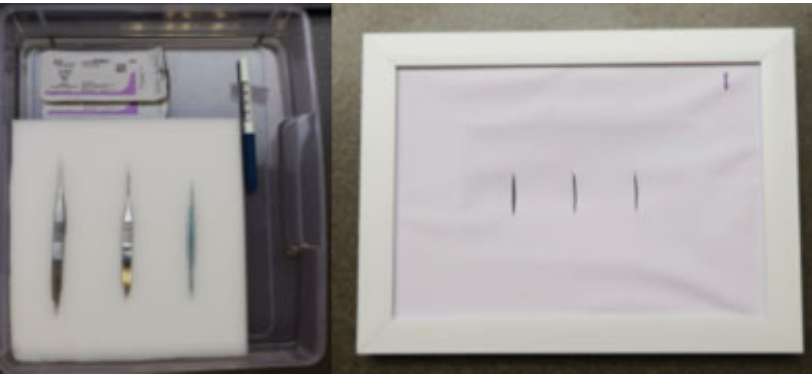

Fig. 8 Wet laboratory kits were received by students and used for virtual suturing instruction.

\section{References}

1 Woolliscroft JO. Innovation in response to the COVID-19 pandemic crisis. Acad Med 2020;95(08):1140-1142

2 Lorenzo-Alvarez R, Ruiz-Gomez MJ, Sendra-Portero F. Medical students' and family physicians' attitudes and perceptions toward radiology learning in the second life virtual world. AJR Am J Roentgenol 2019:1-8

3 Mian A, Khan S. Medical education during pandemics: a UK perspective. BMC Med 2020;18(01):100

4 McKinley SK, Hashimoto DA, Mansur A, et al. Feasibility and perceived usefulness of using head-mounted cameras for resident video portfolios. J Surg Res 2019;239:233-241

5 Chick RC, Clifton GT, Peace KM, et al. Using technology to maintain the education of residents during the COVID-19 pandemic. J Surg Educ 2020;77(04):729-732

6 Oldenburg R, Marsch A. Optimizing teledermatology visits for dermatology resident education during the COVID-19 pandemic.J Am Acad Dermatol 2020;82(06):e229

7 Koumpouras F, Helfgott S. Stand together and deliver: challenges and opportunities for rheumatology education during the COVID-19 pandemic. Arthritis Rheumatol 2020;72(07): 1064-1066

8 Dedeilia A, Sotiropoulos MG, Hanrahan JG, Janga D, Dedeilias P, Sideris M. Medical and surgical education challenges and innovations in the COVID-19 era: a systematic review. In Vivo 2020;34 (3, Suppl):1603-1611

9 Hollander JE, Carr BG. Virtually perfect? Telemedicine for Covid19. N Engl J Med 2020;382(18):1679-1681

10 Graubart EB, Waxman EL, Forster SH, et al. Ophthalmology objectives for medical students: revisiting what every graduating medical student should know. Ophthalmology 2018;125(12): 1842-1843

11 Association of American Medical Colleges. Important guidance for medical students on clinical rotations during the coronavirus (COVID-19) outbreak. Accessed December 4, 2020 at: https:// www.aamc.org/news-insights/press-releases/important-guidance-medical-students-clinical-rotations-during-coronaviruscovid-19-outbreak

12 Wendt S, Abdullah Z, Barrett S, et al. A virtual COVID-19 ophthalmology rotation. Surv Ophthalmol 2021;66(02):354-361

13 Borgersen NJ, Henriksen MJ, Konge L, Sørensen TL, Thomsen AS, Subhi Y. Direct ophthalmoscopy on YouTube: analysis of instructional YouTube videos' content and approach to visualization. Clin Ophthalmol 2016;10:1535-1541

$14 \mathrm{Pj} \mathrm{N}$, Nuova PJ. Evaluation of the use of the Eyesi virtual reality surgical simulator by residents and medical specialists in the Argentine Council of Ophthalmology. J Surg 2020;6(03):. Doi: 10.16966/2470-0991.213

15 Succar T, Zebington G, Billson F, et al. The impact of the Virtual Ophthalmology Clinic on medical students' learning: a randomised controlled trial. Eye (Lond) 2013;27(10):1151-1157 
16 Ashrafzadeh S, Imadojemu SE, Vleugels RA, Buzney EA. Strategies for effective medical student education in dermatology during the COVID-19 pandemic. J Am Acad Dermatol 2021;84(01):e33-e34

17 Chao TN, Frost AS, Brody RM, et al. Creation of an interactive virtual surgical rotation for undergraduate medical education during the COVID-19 pandemic. J Surg Educ 2021;78(01): 346-350

18 Tsui E, Wells MB, Mohamed M, Felix CM, Giaconi JA. Virtual ophthalmology rotations-a real possibility during the COVID19 pandemic and beyond. J Acad Ophthalmol 2020;12(02): e195-e199

19 Wittbold KA, Baugh JJ, Yun BJ, Raja AS, White BA. iPad deployment for virtual evaluation in the emergency department during the COVID-19 pandemic. Am J Emerg Med 2020;38(12):2733-2734

20 Oladeji LO, Raley JA, Smith S, Perez JL, McGwin G, Ponce BA. Behind the match process: is there any financial difference lurking below the specialty of choice? Am Surg 2016;82(12): 1163-1168

21 Winterton M, Ahn J, Bernstein J. The prevalence and cost of medical student visiting rotations. BMC Med Educ 2016;16(01): 291

22 Patel SB, Kelly LD. Visiting student away rotations in ophthalmology: a study of medical students' experiences and perspectives. Nepal J Ophthalmol 2020;12(01):e52-e56

23 Boyd CJ, Inglesby DC, Corey B, et al. Impact of COVID-19 on away rotations in surgical fields. J Surg Res 2020; 255:96-98
24 Succar T, Grigg J, Beaver HA, Lee AG. A systematic review of best practices in teaching ophthalmology to medical students. Surv Ophthalmol 2016;61(01):83-94

25 Zhang $\mathrm{HH}$, Hepschke JL, Shulruf B, et al. Sharpening the focus on ophthalmology teaching: perceptions of medical students and junior medical officers. Clin Exp Ophthalmol 2018;46(09): 984-993

26 Xierali IM, Nivet MA, Wilson MR. Current and future status of diversity in ophthalmologist workforce. JAMA Ophthalmol 2016; 134(09):1016-1023

27 Higgins E, Newman L, Halligan K, Miller M, Schwab S, Kosowicz L. Do audition electives impact match success? Med Educ Online 2016;21:31325

28 Quesada PR, Solis RN, Diaz RC, Kraft SM. Otolaryngology residency application during the SARS-CoV-2 (COVID-19) pandemic. Otolaryngol Head Neck Surg 2020;163(01):89-90

29 Bradford CA. Basic Ophthalmology for Medical Students and Primary Care Residents. 7th ed. San Francisco: American Academy of Ophthalmology; 1999

30 American Academy of Ophthalmology. Medical students interactive cases. Accessed December 29, 2020 at: https://www.aao.org/interactive-cases/

31 Yung R. Indiana University School of Medicine Department of Ophthalmology. Accessed December 29, 2020 at: https://radtf. iuhealth.org/eye/QMachine.ASP?UID=HOMEPAGE

32 Young B, Pouw A. Eyes for Ears: An OKAPS Review Podcast for Residents. Accessed December 29, 2020 at: podcast. 